\title{
Heterogeneous Response to Marine Reserve Formation: A Sorting Model approach
}

\author{
Junjie Zhang · Martin D. Smith
}

Accepted: 11 November 2010 / Published online: 1 December 2010

(C) The Author(s) 2010. This article is published with open access at Springerlink.com

\begin{abstract}
The bioeconomic impacts of spatial fisheries management hinge on how fishing vessels reallocate their effort over space. However, empirical studies face two challenges: heterogeneous behavioral responses and unobservable resource abundance. This paper addresses these two problems simultaneously by using an unusual data set and an estimation technique developed in the industrial organization literature. We apply the methods to location and species choices in the Gulf of Mexico reef-fish fishery. The models are used to explore spatial effort substitution in response to two marine reserves. Individual attributes from a survey of vessel captains are linked to each fisherman's observed daily trip information to control for observable heterogeneity. Some unobservable abundance information is captured by location- and species-specific constants and estimated by contraction mapping. The empirical results confirm that there is significant heterogeneity in fishermen's response to the formation of marine reserves. They also show that ignoring unobservable abundance information will lead to significant bias in predicting spatial fishing effort.
\end{abstract}

Keywords Marine reserves · Locational sorting · Heterogeneous behavior · Survey

JEL Classification Q22 · C35

\section{Introduction}

In the last decade, there has been an explosion of interest in using spatial tools such as marine reserves (no-take zones) to manage marine resources. Bioeconomic modeling unequivocally shows that the effects of marine reserves depend critically on what happens outside the

J. Zhang $(\otimes)$

School of International Relations \& Pacific Studies, University of California, San Diego, USA

e-mail: junjiezhang@ucsd.edu

M. D. Smith

Nicholas School of the Environment and Department of Economics, Duke University, Durham, USA

e-mail: marsmith@duke.edu 
reserves (Hannesson 1998; Sanchirico and Wilen 2001; Smith and Wilen 2003; Costello and Polasky 2008). In spite of this message, virtually nothing is known empirically about what happens outside existing reserves. For reserves that are in place, researchers have not studied how reserve establishment affects the spatial pattern of exploitation in the remaining open areas.

There are two major challenges in attributing behavioral patterns across space to the policy change. First, marine reserves may induce heterogeneous reallocations of fishing effort, and modeling a representative agent masks this heterogeneity. By analyzing micro-data in a model that controls for the spatio-temporal drivers of behavior and individual heterogeneity, we can isolate the effect of a reserve. Second, resource abundance is not directly observable, but omitting this variable will cause bias in estimation. We deal with this problem by including dummy variables that control for spatial- and species-explicit abundance information that is time invariant, in addition to including catch-per-unit-effort as a proxy for time varying abundance.

We model repeated decisions about target species and fishing ground in a discrete choice sorting model framework. Our approach draws on the industrial organization literature on product differentiation (Berry 1994; Berry et al. 1995) and an emerging literature on spatial sorting in public economics (Bayer and Timmins 2005, 2007; Timmins and Murdock 2007). We incorporate observable heterogeneity from the survey data and permit records as interaction terms. Choice-specific constants are used to control for unobservable information about the attractiveness of fishing sites. These constants are solved for using the contraction mapping approach.

In this paper, we quantify the behavioral responses of the Gulf of Mexico reef-fish fleet to two recently established marine reserves. We have an unusually rich data set that merges daily observations of individual vessels from fishing logbooks, daily price data from landings tickets, boat information from federal permit files, and demographic data that we collected in a mail survey of fishing captains. We find that vessel responses to marine reserves are mixed. Failure to control for heterogeneity produces substantively different predictions about the post-reserve spatial distribution of fishing effort. We also find that failure to control for unobservable choice-specific constants leads to dramatic changes in the inferred effects of reserves. There is thus an important role for micro-econometrics in policy debates about marine reserve formation.

In the next section, we provide further motivation and background on discrete choice fisheries models. Section 3 develops our sorting model of fishing behavior, Sect. 4 discusses our unique data set, and Sect. 5 presents results. The final section discusses the results and offers directions for future research.

\section{Background and Motivation}

The central motivation for our empirical analysis is that managers need to know how fishing fleets respond to spatially delineated policies like marine reserves. Because reserves manage people spatially, it is crucial to understand individual preferences across locations, and these spatial preferences can be inferred from locational sorting behavior. With spatial preference information, fishery managers can predict the redistribution of fishing effort after forming a reserve. Managers can thus to avoid unintended outcomes such as increasing fishing pressure in other areas when reducing fishing effort in a protected area (Wilen et al. 2002). In an ex ante analysis Smith and Wilen (2003), show that the qualitative long-run impacts of a marine reserve in the California sea urchin fishery are reversed when the bioeconomic model 
includes empirically calibrated spatial behavior over fishing grounds. That is, a reserve that would appear to generate a long-run harvest increase in a detailed biological model instead leads to a long-run harvest loss in the empirically based bioeconomic model. This conclusion is strengthened when the model allows for spatial adjustment over ports in addition to fishing grounds (Smith and Wilen 2004). Kahui and Alexander (2008) find similar results in an empirically based bioeconomic model of the New Zealand abalone fishery. These studies naturally raise the question of what happens to behavior ex post. For fisheries in which reserves have been put in place during the sample period, does effort intensify in the surrounding areas? There is at least anecdotal evidence that fishing effort clusters on the borders of large no-take zones off the coast of New England, a phenomenon known as "fishing the line" (Holland 2004).

In this paper, we analyze the reef-fish fishery in the Gulf of Mexico (GM). In June of 2000, the GM Fishery Management Council (GMFMC) formed two marine reserves in the northeastern Gulf. Researchers have found that after 4.5 years the aggregate effect of these reserves was a decrease in reef-fish yield (Smith et al. 2006). However, the aggregate effect may be masking substitution across target species. Did fishermen respond to the reserves by switching to other statistical areas, changing their gear configurations, or targeting different species? Alternatively, were behavioral responses minimal, in which case the yield decreases directly reflect losses in fishable biomass? This is an important question for GM managers and for the broad debate about the effectiveness of marine reserves. Compared to the New England case of fishing the line (Holland 2004), fishing locations in GM are only reported by National Marine Fisheries Service (NMFS) zone; the data in GM are spatially coarser. Fishing the line cannot be observed directly, but it is possible to explore whether fishing intensifies within the NMFS zone that contains the reserve by adapting discrete choice methods.

The tools for understanding heterogeneity and modeling individual fishing behavior have only recently begun to emerge in the broader fisheries economics and econometrics literature. For quite some time, authors have used discrete choice models to study broad fishery choice (Bockstael and Opaluch 1983), entry and exit decisions (Ward and Sutinen 1994), and choice of fishing grounds (Curtis and Hicks 2000; Dupont 1993; Eales and Wilen 1986; Hicks and Schnier 2006; Larson et al. 1999). Recent work has emphasized the importance of two types of behavioral heterogeneity: state dependence and preference heterogeneity. Habit persistence, i.e. fishermen tend to do what they have been doing (Holland and Sutinen 2000), is one form of state dependence in which past choices directly affect future ones. Behavioral heterogeneity then is a result of different vessels having made different choices in the past. We do not explicitly model state dependence in this paper but note the potential importance of extending the sorting model to include it in future research. In contrast, variation in individual preferences is another source of spatial behavioral heterogeneity and can be modeled with McFadden and Train (2000) Mixed Logit. With this approach Mistiaen and Strand (2000), analyze location choice Eggert and Tveteras (2004); analyze gear choice; and Strand (2004) looks at spatial variation in risk preferences of GM longliners. Smith (2005) combines these two strands of the literature (state dependence and preference heterogeneity), adding more dimensions to the random parameter vector in a Mixed Logit model of location choice. Finally Smith and Wilen (2005), examine preference heterogeneity in fishing by estimating separate probit models for each individual and bootstrapping standard errors to test hypotheses about the population of fishermen. They demonstrate that behavioral responses to physical risk, financial risk, and other aspects of the economic environment are heterogeneous.

Understanding fishing behavior for managers also requires understanding how multiple individual discrete decisions unfold over space and time. Three examples in GM include participation (when to go fishing), species target, and fishing location choice. All of these, 
combined with the amount and type of gear deployed, are critical determinants of fishing effort. Nested logit models have been used to study joint participation and location choice in fisheries (Berman et al. 1997; Smith 2002; Smith and Wilen 2003), but these models still impose a very restrictive substitution pattern for aggregate outcomes. A model that has more flexibility in substitution patterns and that can incorporate a rich parameterization of heterogeneity is essential to learning more about fishing behavior. A sorting approach provides a flexible model of aggregate outcomes. Because we have permit and survey data, we depart from the emphasis in the literature on unobserved heterogeneity and instead model observed heterogeneity.

\section{The Empirical Model}

We model the choice of fishing location and species jointly in a random utility framework. The utility of individual $i$ choosing location-species alternative $j$ at choice occasion $t$ is:

$$
u_{i j t}=v_{i j t}+\varepsilon_{i j t},
$$

where $\varepsilon_{i j t}$ is an idiosyncratic error term. Following Bayer and Timmins (2005), the deterministic term $v_{i j t}$ is decomposed into choice-specific attributes interacted with individual-specific attributes, as well as a choice-specific constant:

$$
v_{i j t}=\left(x_{i}^{\prime} \beta_{1}\right) \text { Reserve }_{j t}+\left(x_{i}^{\prime} \beta_{2}\right) P_{j t}+\left(x_{i}^{\prime} \beta_{3}\right) C P U E_{j t}+\left(x_{i}^{\prime} \beta_{4}\right) D_{i j}+\delta_{j} .
$$

In this form, $x_{i}$ includes individual attributes such as vessel speed, vessel length, income, share of income from commercial fishing, and age. Reserve ${ }_{j t}$ indicates the marine reserve policy. Reserve ${ }_{j t}=1$ for alternative $j$ at time $t$ if there is a marine reserve present in that area at that time. Otherwise, it is zero. $P_{j t}$ is species-specific monthly price including red snapper, grouper, and other reef species. $C P U E_{j t}$ is species- and location-specific monthly catch-per-unit-effort (CPUE). $D_{i j}$ is the distance from home port of $i$ to location $j$. Since we do not observe travel costs for each trip, distance is used as a proxy.

The observed individual heterogeneity is thus a function of individual attributes. As such, the net effect of each choice-specific attribute has a constant term and an effect of individualspecific attributes. The model setup is an alternative to a Mixed Logit model with random parameters (McFadden and Train 2000). However, assuming that the parameter heterogeneity is observable, this model significantly reduces the computational intensity, avoids the introduction of simulation noise, and allows for economic interpretations of individual coefficient estimates.

The choice-specific constant is designated by $\delta_{j}$. The constant captures unobservable location- and species-heterogeneity such as carrying capacity that is attributable to habitat type, amount, and quality. All of these can theoretically change over time, but they are effectively static over the time horizon that we explore. Locations with more grouper habitat, for instance, or higher quality grouper habitat will tend to be more profitable places to fish for grouper. Ceteris paribus, these locations will have more grouper abundance. An important caveat about the choice-specific constants in our model is that they do not vary over time and thus do not capture time-varying resource abundance. CPUE, which does vary over time in our model, proxies for time-varying aspects of abundance as it typically does in bioeconomic fisheries models. Another caveat about our choice-specific constants is that other unobservables that do not vary across individuals and time may be also lumped into the $\delta^{\prime}$ s. Thus, the choice-specific constants likely contain key abundance information, but they are at best noisy abundance indicators. 
In spite of difficulties in interpreting choice-specific constants in our model, including them helps to avoid omitted variable bias. The selection of marine reserves is likely dependent on the unobservable habitat information (at least unobserved by us) and thus correlated with the $\delta^{\prime}$ s. Therefore, leaving out choice-specific constants in this application almost certainly would lead to omitted variable bias.

Assuming that $\varepsilon_{i j t}$ is i.i.d. with a type I extreme value distribution, the probability of individual $i$ choosing alternative $j$ at choice occasion $t$ is,

$$
p_{i j t} \equiv \operatorname{Pr}\left\{y_{i t}=j \mid v_{i j t}\right\}=\frac{\exp \left(v_{i j t}\right)}{\sum_{s \in J_{t}} \exp \left(v_{i s t}\right)} .
$$

The choice set $J_{t}$ varies over time due to the seasonal closure policy for red snapper and grouper species. $J_{t}$ also includes the alternative of non-reef fishing as the baseline utility, which is normalized to zero. The alternative-specific constants are estimated through Berry (1994) and Berry et al. (1995) contraction mapping:

$$
\hat{\delta}^{\text {new }}=\hat{\delta}^{\text {old }}+\ln (s)-\ln \left(\widehat{s}\left(\hat{\delta}^{\text {old }} ; \widehat{\beta}\right)\right),
$$

where $s$ is the observed share vector for alternatives and

$$
\widehat{s}_{j}=\frac{1}{N} \sum_{i, t} \widehat{p}_{i j t} \text {. }
$$

In this form, $N$ is the total number of fishing trips. We follow the same estimation routine as the one in Murdock (2006) and Timmins and Murdock (2007). The above contraction mapping problem is solved iteratively, in which the fixed point iteration (4) is nested into the maximum likelihood estimator of (3). The routine searches over values of $\beta^{\prime}$ s, where for each guess of $\beta$, the associated optimal $\delta$ is found via the contraction. The routine stops when the overall likelihood is maximized.

Some notes on the motivation for using contraction mapping are in order here. Given the large data sets that are common in fishing logbooks and the large number of choices $(J=40)$ when crossing three species aggregates with 13 fishing locations (and including a choice for non-reef fishing normalized to zero), contraction mapping is computationally more feasible and stable than putting in choice-specific dummy variables. Still, with just 40 choices, it is possible to estimate these coefficients with dummy variables using conventional maximum likelihood. The more compelling motivation for this approach is that population level information is used to identify the choice-specific constants. When we link our analysis to the survey data, we necessarily exclude individuals who did not respond to the survey. We are able to include non-respondents in the population. The asymptotic properties of this approach stem from the use of population shares, though often researchers end up using sample data for the contraction. Here we are able to use the sample to estimate coefficients on the covariates and the population data to solve for the fixed effects.

For comparing models that incorporate heterogeneity and choice-specific constants, we are interested in the "marginal" effect of forming a marine reserve. The effect, strictly speaking, is not "marginal" because locations either contain a reserve or they do not. Thus, the definition of the marginal effect is:

$$
\operatorname{Pr}\{y=j \mid \bar{X}, \text { Reserve }=1\}-\operatorname{Pr}\{y=j \mid \bar{X}, \text { Reserve }=0\},
$$

where $y$ is the choice variable and $\bar{X}$ is the mean of all explanatory variables excluding the reserve dummy. It is also possible to estimate the individual-specific marginal effect. This is 
particularly useful when this model is used to predict the location and species distribution of effort in the case of heterogeneous fishing vessels.

\section{Data}

We constructed a unique data set that we believe is distinguished from previous research in fisheries economics. The data set combines: (1) daily choice records from federal logbook data on the Gulf of Mexico reef fish fishery, (2) federal commercial fishing permit data, (3) species-level price data from Florida landings tickets, and (4) a social survey of reef fish captains. The integration of a social survey with repeated choices from logbooks is unique.

The logbook data reports fishing location by National Marine Fisheries Service fishing zones and catch by species. Our data set contains a complete set of records for 1993-2004. For purposes of analyzing discrete location choices and species target decisions, we aggregate the 62 reef fish species into three groups: grouper, snapper, and other reef fish. The aggregation is based on the economic importance of these species and the grouping of similar management policies. Other reef fish are caught with similar gear, and there is an overarching reef-fish permit that is required to harvest any of these species groups.

The catch-per-unit-effort is computed from the aggregate monthly catch and effort information from the logbook. We define effort as number of trip days visiting a zone and targeting a species group in a month based on the population fishing data. We use monthly data to ensure that the covariate matrix in the discrete choice model is not sparse. Some zone-species combinations have zero effort at finer temporal aggregations, e.g. weekly. We measure the distance from home port to the center of the fishing ground. Distance is used as a proxy for travel costs.

Permit data provide information about vessel length for each of the unique vessels that appear in the logbook data. Florida landings tickets were provided by the Florida Marine Research Institute (FMRI), a division of the Florida Department of Fish and Wildlife. We use these data to develop weighted average price time series for each of our species aggregates. Fish price is monthly and species-specific.

We conducted a social survey of reef fish captains by mail in 2005. A unique aspect of our survey was the ability to link repeated fishing choices to the individual survey respondents. This entailed cooperation with both state and federal agencies to enable us to track individual vessels over space and time, associate the survey responses with these records, restrict our access to individual identifiers such as names and addresses (essential for the way in which we obtained informed consent), and prevent regulators from having access to the survey data (an important promise made to survey respondents in order to ensure a high response rate).

To this end, NOAA Fisheries provided FMRI with a complete permit data base with vessel codes and names and addresses of permit holders. FRMI generated a unique survey identifier associated with each vessel code and stripped the identifying information about reef fish captains (e.g. names and addresses) from the version of the file sent to us. We prepared the mail surveys with the unique survey codes, and FMRI did the mailing on our behalf. The pre-paid return envelopes were addressed to us. In this way, we were able to assure reef fish captains that their survey responses would not be made available to state or federal regulators (a significant concern of many commercial fishermen).

Survey administration followed the Dillman (2000) method. We first developed a draft survey and ran a focus group with reef fish captains in the northeastern Gulf. As a result of the focus group, we revised the questionnaire and then conducted a very limited pre-test $(n=3)$ and extensive phone debriefings with each of the pre-test participants. We administered five 


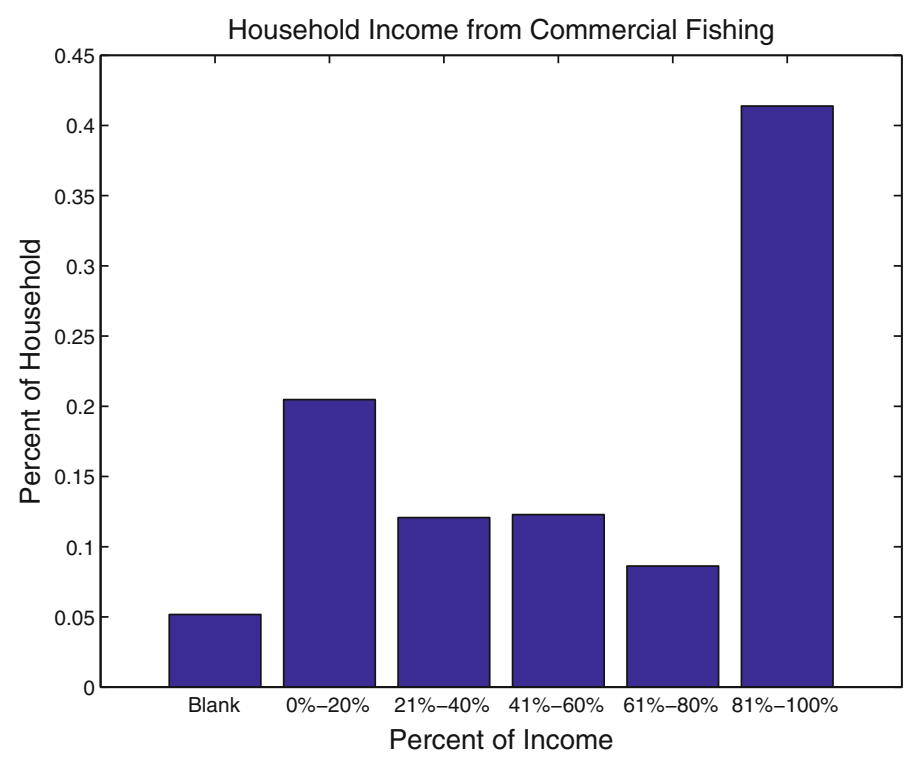

Fig. 1 Survey respondents

separate mailings: (1) a pre-notification post card, (2) the survey along with a gift, (3) a follow-up reminder post card, (4) a second copy of the survey, and (5) a third copy of the survey. With the initial mailing of each survey, we included a gift of a DVD with video footage from inside the Madison-Swanson Marine Reserve. At this stage, we are using a very small portion of the information that we collected.

We mailed out 1,079 surveys that covered all reef-fish permit holders in the data base, of which 495 surveys returned with a response rate at $45.9 \%$. If we remove blanks with "No Longer Fishing in Gulf", incorrect addresses, and duplicate permit holders, the total number of surveys is 993 with 464 surveys returned (or 46.7\%). Respondents' share of income from commercial fishing is depicted in Fig. $1 .^{1}$

One drawback of using survey data in conjunction with logbooks is that we are limited by both survey non-respondents and non-responses to particular survey questions. As a first step, we use a small subset of the available survey data, including questions on vessel speed, total income, captain's age, and percentage of income derived from commercial fishing. This leaves us with 373 individuals and 28,399 total observed fishing trips. Of the 28,399 fishing trips, 2,307 choose the non-reef fishing alternative and the remaining 26,092 choose one of our reef-fish species/location combinations. Because the participation choice (fishing/no fishing) is not modeled, the data is an unbalanced panel. We have no information about the fishermen who did not go fishing. In this case, a choice occasion is a distinct fishing trip in which the vessel chooses one of our 39 species/NMFS zone combinations or the baseline non-reef trip alternative. The time step is daily. Most reef-fish trips are one-day trips. A multiple-day trip is regarded as multiple trips. A two-day trip is two trips, a three-day trip is three trips, and so forth. The summary statistics of the variables used in regression are reported in Tables 1 and 2.

\footnotetext{
${ }^{1}$ By using the permit data, we can test for differences in survey respondents and non-respondents. We fail to reject the hypotheses that the mean captain age and mean vessel length for survey respondents differ from those of non-respondents, suggesting that our sample is not biased.
} 
Table 1 Summary statistics: continuous variables

\begin{tabular}{lllllr}
\hline Variable & Description & Mean & SD & Min & Max \\
\hline PRICE & Monthly fish price & 1.5879 & 0.7264 & 0.0000 & 2.7817 \\
CPUE & Monthly catch-per-unit-effort $(\times 100)$ & 0.3516 & 0.5167 & 0.0000 & 8.9854 \\
DISTANCE & Distance from home port to fishing ground & 4.0659 & 2.3944 & 0.1355 & 15.0458 \\
SPEED & Vessel speed $(\times 100)$ & 0.1587 & 0.0825 & 0.0000 & 0.5000 \\
VLENGTH & Vessel length $(\times 100)$ & 0.3587 & 0.0852 & 0.1700 & 0.7300 \\
AGE & Captain age $(\times 100)$ & 0.5065 & 0.1031 & 0.2500 & 0.7500 \\
\hline
\end{tabular}

Table 2 Summary statistics: discrete variables

\begin{tabular}{lllr}
\hline & & \multicolumn{2}{l}{ Percentage } \\
\cline { 2 - 3 } Variable & Explanation & No & Yes \\
\hline RESERVE & Fishing around marine reserves & 93.15 & 6.85 \\
INCOME & Household income $<35$ K USD & 38.40 & 61.60 \\
COMMERCIAL & Income from commercial fishing $>60 \%$ & 22.56 & 77.44 \\
\hline
\end{tabular}

\section{Results}

We estimate four econometric models with the following specifications: (1) a full model, (2) excluding the choice-specific constants, (3) excluding the observable heterogeneity, and (4) excluding both constants and observable heterogeneity. The estimation results are reported in Table 3. The full model is the preferred specification and the others are used for robustness checks.

The ex ante expected signs of price, CPUE, and distance are: a higher species price increases its attractiveness for fishing, a higher CPUE increases the probability of fishing for a species in a specific location, and longer travel distances decrease the probability of fishing at a particular site. The ex ante expected sign of the reserve effect is less obvious. On the one hand, we expect that the reserve eliminates some of a fishing ground and thus reduces the profitability of fishing in the surrounding zone (Smith et al. 2006). But on the other hand, from our survey $33 \%$ of fishermen report that marine reserves in the Gulf of Mexico have increased fishing yields of groupers and other reef fish, and there is some independent evidence that the reserves have started to benefit grouper population dynamics (Smith et al. 2007).

The preferred model specification (1) yields highly significant estimates. Because the full model has interaction terms, the net effects of covariates are individual-specific and need to be evaluated with individual attributes. The constant effects of covariates (top four lines of Table 3 for specifications 1 and 2) should not be interpreted in isolation. It is the net effect that matters. As an example, the full model estimates the following net effect of marine reserves:

$$
\begin{aligned}
x_{i}^{\prime} \hat{\beta}_{1}= & -1.0843-1.1129 * \mathrm{SPEED}_{i}+1.9285 * \mathrm{VLENGTH}_{i} \\
& -0.0288 * \mathrm{COMMERCIAL}_{i}+2.4368 * \mathrm{AGE}_{i} .
\end{aligned}
$$

In this form, SPEED is vessel speed, VLENGTH is vessel length, COMMERCIA is an indicator variable which is one if income from commercial fishing is greater than $60 \%$, and AGE 
Table 3 Estimation results

\begin{tabular}{|c|c|c|c|c|c|c|c|c|c|}
\hline \multirow{2}{*}{$\begin{array}{l}\text { Choice } \\
\text { variables }\end{array}$} & \multirow{2}{*}{$\begin{array}{l}\text { Individual } \\
\text { variables }\end{array}$} & \multicolumn{2}{|l|}{ (1) } & \multicolumn{2}{|l|}{ (2) } & \multicolumn{2}{|l|}{ (3) } & \multicolumn{2}{|l|}{ (4) } \\
\hline & & Estimate & Std Err & Estimate & Std Err & Estimate & Std Err & Estimate & Std Err \\
\hline RESERVE & & -1.0843 & 0.2191 & -0.7573 & 0.2064 & 0.5012 & 0.0240 & 0.3195 & 0.0231 \\
\hline PRICE & & 9.8218 & 0.1452 & 3.0227 & 0.0925 & 5.0358 & 0.0161 & 0.6979 & 0.0107 \\
\hline CPUE & & 0.7858 & 0.1199 & 1.0124 & 0.0884 & 0.5626 & 0.0137 & 0.8616 & 0.0104 \\
\hline DISTANCE & & -4.0275 & 0.0790 & -2.7893 & 0.0598 & -1.8170 & 0.0085 & -1.0514 & 0.0071 \\
\hline \multirow[t]{5}{*}{ RESERVE } & SPEED & -1.1129 & 0.3272 & -1.4811 & 0.3212 & & & & \\
\hline & VLENGTH & 1.9285 & 0.3422 & 0.9603 & 0.3108 & & & & \\
\hline & INCOME & -0.0288 & 0.0628 & -0.1176 & 0.0603 & & & & \\
\hline & COMMERICAL & -0.1543 & 0.0535 & -0.0585 & 0.0509 & & & & \\
\hline & AGE & 2.4368 & 0.2634 & 2.1665 & 0.2526 & & & & \\
\hline \multirow[t]{5}{*}{ PRICE } & SPEED & -2.5071 & 0.2006 & -1.8229 & 0.1345 & & & & \\
\hline & VLENGTH & -2.8714 & 0.2101 & -2.0031 & 0.1324 & & & & \\
\hline & INCOME & 0.0256 & 0.0398 & -0.1741 & 0.0267 & & & & \\
\hline & COMMERICAL & -0.0040 & 0.0352 & -0.0850 & 0.0228 & & & & \\
\hline & AGE & -3.0736 & 0.1729 & -2.1495 & 0.1097 & & & & \\
\hline \multirow[t]{5}{*}{ CPUE } & SPEED & -0.7348 & 0.1878 & -0.6927 & 0.1355 & & & & \\
\hline & VLENGTH & 2.0039 & 0.1639 & 0.8730 & 0.1192 & & & & \\
\hline & INCOME & -0.3646 & 0.0399 & -0.2180 & 0.0287 & & & & \\
\hline & COMMERICAL & -0.1433 & 0.0317 & -0.0476 & 0.0226 & & & & \\
\hline & AGE & -0.7258 & 0.1429 & -0.3008 & 0.1049 & & & & \\
\hline \multirow[t]{5}{*}{ DISTANCE } & SPEED & -0.5370 & 0.1151 & -0.7193 & 0.0963 & & & & \\
\hline & VLENGTH & 0.1549 & 0.1092 & 0.9541 & 0.0823 & & & & \\
\hline & INCOME & 0.9648 & 0.0276 & 0.6095 & 0.0228 & & & & \\
\hline & COMMERICAL & 0.1654 & 0.0185 & 0.0122 & 0.0150 & & & & \\
\hline & AGE & 2.6051 & 0.0917 & 1.8809 & 0.0717 & & & & \\
\hline \multicolumn{2}{|c|}{ Choice-specific fixed effects } & \multicolumn{2}{|c|}{ Yes } & \multicolumn{2}{|c|}{ No } & \multicolumn{2}{|c|}{ Yes } & \multicolumn{2}{|c|}{ No } \\
\hline
\end{tabular}

Number of observations: 28,399. Number of individuals: 373. Number of alternatives: 40. The dependent variable is discrete choice over 40 options. The explanatory variables include choice-specific attributes and their interactions with individual-specific attributes. Model (1) is the full model. Model (2) has no choice-specific fixed effects. Model (3) has no individual attributes (second column) from the survey. Model (4) has neither survey data nor fixed effects

is captain age. The term -1.0843 does not have meaning on its own. This term combined with interactions determine the net effect of reserves on behavior. In models without interactions (specifications 3 and 4), the constant effect is equivalent to the net effect and can be interpreted. Similar to the reserve effect, we can derive the net effects for price, CPUE, and distance. Most estimates on individual attributes are statistically significant, suggesting that the observable sources of heterogeneity are partly driving the observed behavior in the fishery.

Using the parameter estimates from the preferred model and the observed individual attributes, we evaluate the individual-specific coefficients for reserve, price, CPUE, and distance. The estimated distributions of individual responses are plotted in Fig. 2, which are smoothed by nonparametric kernel functions. The net effects of price and CPUE are positive, and the 


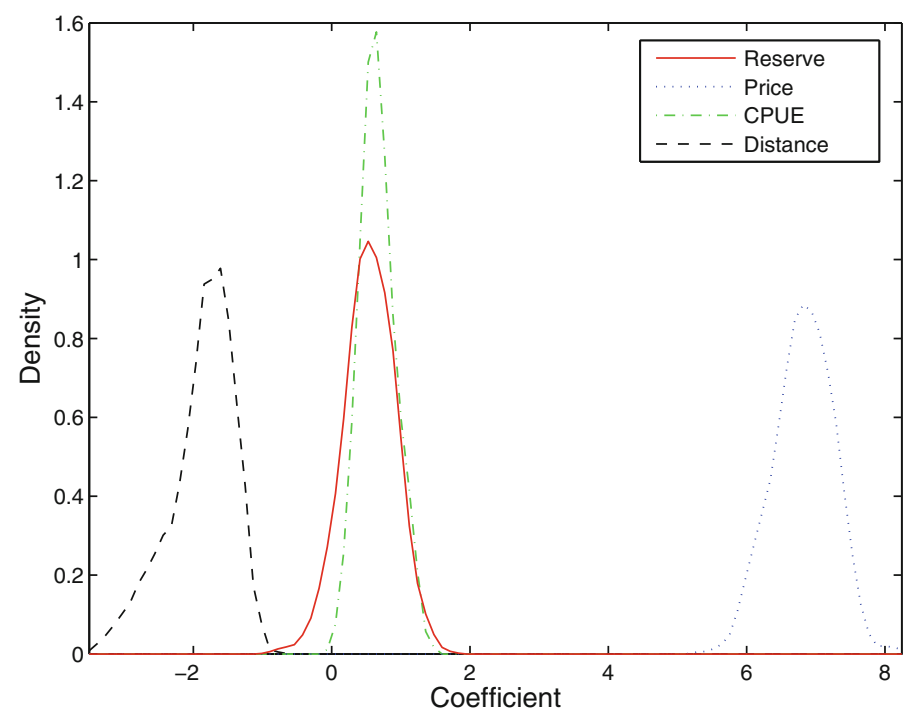

Fig. 2 Individual-specific coefficients

net effects of distance are all negative. For these variables, although the signs are the same for every fisherman, the magnitudes of the effects are different for each. In contrast, the responses to the marine reserve policy are mixed. The reserve density straddles the zero point, which means some fishermen go fishing more around the reserves but others fish less.

The heterogeneous individual behavioral pattern in response to the marine reserve policy is revealed by the observed information. Interestingly, the stated preference obtained from the survey conveys similar information. When the fishermen were asked if reserves are a bad way to manage fisheries, $28 \%$ answered agree, $32 \%$ were uncertain, and $30 \%$ did not agree. The distribution of fishermen's response to the survey question is depicted in Fig. 3. Although a rigorous approach is needed to confirm that the revealed preference and the stated preference coincide, they appear to be correlated.

Beyond calculating net effects, the interaction terms provide further insights into fishing behavior. One interesting finding is that vessel speed has a negative effect on the tendency to fish in a zone that contains a reserve and also has a negative effect on the tendency to travel long distances. Vessel length, on the other hand, has positive effects on both, though the distance interaction is not significant. These results point to an interesting source of heterogeneity in the fishery. The smaller vessels tend to be faster, but by virtue of being smaller, have less hull capacity and tend to make shorter trips. They may be designed to get to a fishing site quickly and return to port within the same day. Faster vessels thus are more averse to longer travel distances. The opposite is true for large vessels.

Though not all of the income interactions are significant, the CPUE and distance interactions suggest a troubling problem in the reef fish fishery. Lower income individuals are less responsive to changes in CPUE and less responsive to travel distance. ${ }^{2}$ This naturally raises a question about the direction of causality. On the one hand, lower income fishermen are less able to adjust fishing effort to economic conditions than wealthier fishermen, probably due to the inability to obtain information about other fisheries and to afford adjustment costs.

2 One reviewer suggests that this implies a lower cost of fishing effort and a lower travel cost, which would be expected if their opportunity cost of time is lower. 


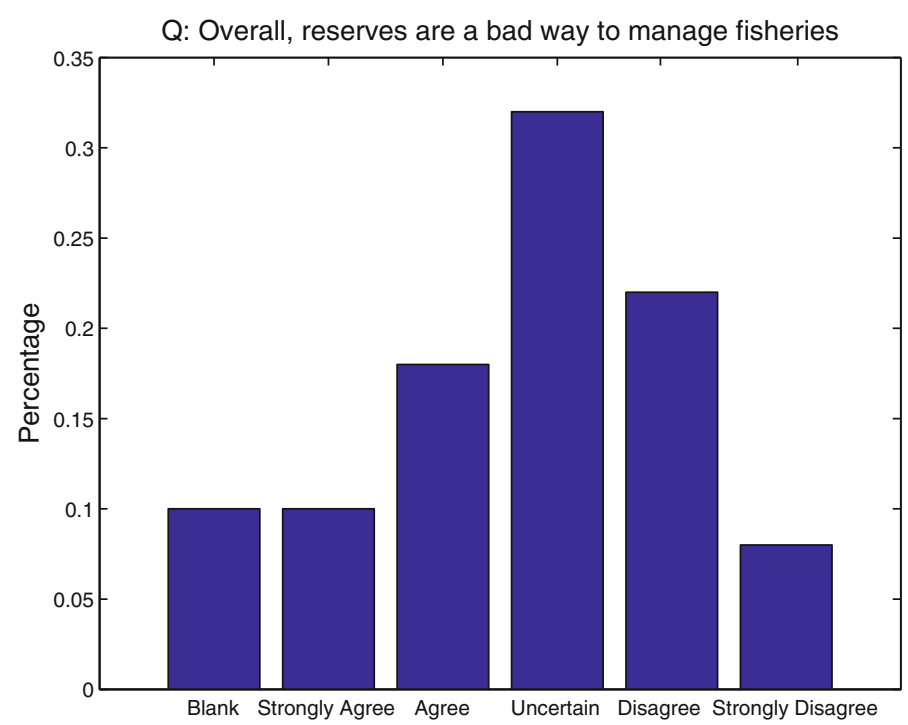

Fig. 3 Mixed views about marine reserves

On the other hand, lower income fishermen might be poor because they are not as good at fishing.

Captain age is another interesting finding. We find that older fishermen are less responsive to marginal changes in all of the economic opportunities. That is, the signs of the captain age interactions are all opposite of what we find in the mean coefficient levels. Holland and Sutinen (2000) suggest that "old habits die hard" for New England fishermen. One interpretation of our model is that older fishermen have formed strong fishing habits and thus are less responsive to changes in the economic environment.

We also run three additional regressions for robustness checks. Model (2) has no choicespecific constants but it yields qualitatively similar results. As for models (3) and (4), the signs of choice-specific attributes can be read from estimates directly. Price, CPUE, and distance all have expected signs. Models without observable heterogeneity predict that fishing effort increase in zones that contain marine reserves. However, different specifications predict significantly different marginal effects. We illustrate the quantitative difference by comparing the marginal effects of marine reserves.

The marginal effect of marine reserves can be estimated according to Eq. (6). Evaluated at the sample means of choice- and individual-specific attributes, the marginal reserve effect predicted by alternative specifications is compared with that of the full model. The ratio of the estimated effects (alternative model/full model) is reported in Table 4 . A ratio of 1 indicates that the alternative specification produces the same effect as the full model, while less than 1 implies underestimation and greater than 1 suggests overestimation.

In Table 4, there are major differences in some of the marginal effects. Accounting for observable heterogeneity and choice-specific constants leads to very different conclusions about the behavioral response of the reef fish fleet to the formation of two marine reserves. These differences appear both in zones that contain the reserves (6 and 8) and in the other zones. With the exception of groupers (species 1), the model that excludes observed heterogeneity but still includes choice-specific constants comes close to estimating the behavioral effect of the reserve from the full model. The results do not hold for grouper most likely 
Table 4 Comparison of marginal effects

\begin{tabular}{|c|c|c|c|c|c|c|c|c|c|}
\hline \multirow[t]{2}{*}{ Area } & \multicolumn{3}{|c|}{ Red snapper } & \multicolumn{3}{|c|}{ Groupers } & \multicolumn{3}{|c|}{ Other reef-fish } \\
\hline & (2) & (3) & (4) & (2) & (3) & (4) & (2) & (3) & (4) \\
\hline 1 & 1355.31 & 6.89 & 1562.95 & 1.55 & 1.48 & 1.77 & 0.04 & 0.93 & 0.04 \\
\hline 2 & 206.72 & 4.79 & 235.65 & 0.58 & 1.25 & 0.65 & 0.04 & 0.96 & 0.04 \\
\hline 3 & 1836.67 & 4.05 & 2019.43 & 0.98 & 1.04 & 1.07 & 0.71 & 0.98 & 0.78 \\
\hline 4 & 1344.84 & 3.54 & 1415.59 & 0.45 & 0.82 & 0.47 & 0.59 & 0.84 & 0.63 \\
\hline 5 & 1193.76 & 3.64 & 1226.49 & 0.47 & 0.85 & 0.48 & 0.69 & 0.92 & 0.71 \\
\hline 6 & 280.14 & 3.38 & 295.74 & 0.22 & 0.87 & 0.23 & 0.39 & 0.92 & 0.41 \\
\hline 7 & 81.51 & 2.77 & 84.28 & 0.27 & 0.79 & 0.27 & 0.36 & 0.82 & 0.37 \\
\hline 8 & 43.00 & 2.43 & 46.42 & 2.83 & 0.99 & 3.03 & 0.94 & 0.96 & 1.02 \\
\hline 9 & 20.02 & 2.01 & 21.51 & 5.18 & 0.88 & 5.52 & 0.65 & 0.84 & 0.70 \\
\hline 10 & 9.48 & 2.14 & 10.53 & 17.64 & 0.96 & 19.46 & 0.53 & 0.83 & 0.59 \\
\hline 11 & 5.10 & 2.03 & 5.88 & 19.34 & 0.98 & 22.18 & 0.47 & 0.87 & 0.54 \\
\hline 12 & 58.44 & 3.03 & 70.39 & 271.86 & 0.98 & 325.37 & 3.79 & 0.95 & 4.59 \\
\hline 13 & 1.13 & 2.28 & 1.36 & 7.61 & 1.05 & 9.11 & 0.17 & 1.07 & 0.21 \\
\hline
\end{tabular}

The table reports the ratio of estimated marginal effects by different specifications (alternative model/full model). Marginal effects are evaluated at sample means of choice- and individual-specific attributes. Model (2) has no choice-specific fixed effects. Model (3) has no individual attributes (second column) from the survey. Model (4) has neither survey data nor fixed effects

because the reserves were formed in part to protect gag and other shallow-water groupers, and thus the overall behavioral response is more pronounced.

It is also interesting to examine the choice-specific constants that can be solved for by contraction mapping. The result is depicted in Fig. 4. Moving along the x-axis, geographically, is moving counter-clockwise through the Gulf of Mexico starting from the southern tip of Florida until Louisiana. Although our choice-specific constants are lumped parameters and thus noisy signals, the figure could be thought of as a picture of average relative abundance over space for the three species aggregates in our model. Unlike a traditional stock assessment model, these stock indices are derived implicitly from the observed behavior of the fishing fleet alone. The pattern for red snapper is consistent with the concentration of the red snapper fishery in the northeastern Gulf of Mexico (Weninger and Waters 2003). Similarly, the pattern for groupers is consistent with the grouper fishery in the eastern Gulf (Coleman et al. 1996).

\section{Discussion}

We present results form a unique data set that allows us to explore the effect of observable heterogeneity on behavioral responses to marine reserves. We find that, in aggregate, marine reserves lead to more intensive fishing in the surrounding areas. Moreover, reserve effects on fishing behavior are sensitive to whether one models behavioral heterogeneity. Collecting survey data and linking it with logbook information is both costly and bureaucratically complicated. Our statistical estimates and comparisons across models indicate that this sort of activity may be worth the effort. Without conducting a survey, an intermediate step for other applications would be to exploit vessel information that exists in permit files together with 


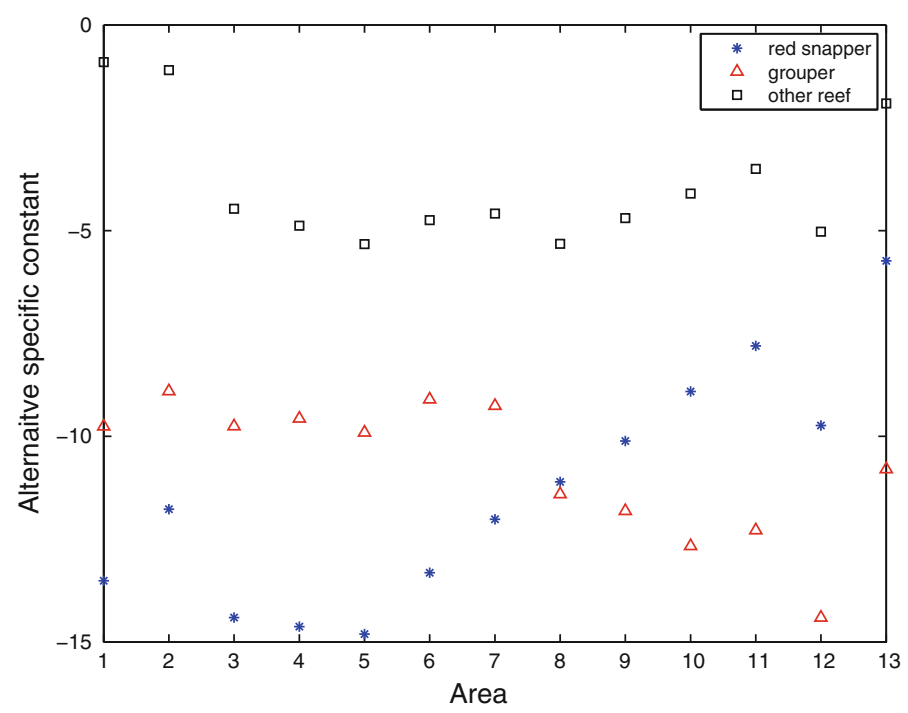

Fig. 4 Choice-specific constants

repeated choices in logbooks. This could become a routine approach for commercial fisheries data in the US and in other countries that collect and electronically code vessel-level logbook data. Our results also show that including choice-specific constants has an even more pronounced effect on behavioral responses to reserves than observable heterogeneity. We demonstrate that the contraction mapping is a convenient method to estimate these choicespecific effects, especially if the number of choices is large and the population information is available. Both of these conditions are likely to be true for federally managed fisheries, particularly as we move towards using more spatial management tools.

The spatial resolution of our data is not sufficient to exploit the power of the sorting model to its fullest potential. One of the strengths of this econometric modeling approach is the ability to decompose the estimation into two stages and use the second stage to disentangle agglomeration or congestion effects from the alternative-specific constant (Timmins and Murdock 2007). We can easily imagine both features existing in fisheries. Agglomeration could arise from some common information about spatially explicit abundance that is not observed by the analyst. Congestion externalities, in contrast, occur when boats fish in close proximity to one another, compete for the same fish, and increase the risks of fishing lines becoming entangled or even boat collisions. The presence of congestion or agglomeration further complicates the interpretation of choice-specific constants. Constants may still contain important ecological information, but the signal is noisier when other factors are lumped into them. This problem points to the need to identify applications of sorting models to fisheries data in which the second-stage decomposition is possible.

A spatial sorting approach like the one presented in this paper has the potential to contribute to emerging policy debates about marine ecosystem management. For example, spatial choice in Alaskan groundfish fisheries (Berman 2006; Berman et al. 2007; Haynie and Layton 2010; Abbott and Wilen 2010) is potentially a fruitful area for future research. In that context, the spatial resolution of fishing data is higher, and there is substantial interest in understanding the effects of micro-spatial closures. Sorting models could also be used to assess the behavioral response to an environmental disturbance. The dead zone in GM (a large area of 
low dissolved oxygen that forms during the summer months due to nutrient enrichment from the Mississippi River) provides an example. If vessels in the GM shrimp fishery react to the dead zone, and a sorting model could help to evaluate the economic consequences of this environmental disturbance.

Open Access This article is distributed under the terms of the Creative Commons Attribution Noncommercial License which permits any noncommercial use, distribution, and reproduction in any medium, provided the original author(s) and source are credited.

\section{References}

Abbott JK, Wilen JE (2010) Voluntary cooperation in the commons? evaluating the sea state program with reduced form and structural models. Land Econ 86(1):131-154

Bayer P, Timmins C (2005) On the equilibrium properties of locational sorting models. J Urban Econ 57(3):462-477

Bayer P, Timmins C (2007) Estimating equilibrium models of sorting across locations. Econ J 117(518): 353-374

Berman M (2006) Modeling spatial choice in ocean fisheries. Mar Resour Econ 21(4):121-125

Berman M, Gregr E, Ishamura G, Sumaila UR, Haley S, Kim H (1997) Estimating net benefits of reallocation: discrete choice models of sport and commercial fishing. Mar Resour Econ 14:307-327

Berman M, Gregr E, Ishamura G, Sumaila UR (2007) Spatial fisheries values in the north pacific. In: Selected paper. Forum of the North American Association of Fisheries Economists. Merida, MX

Berry ST (1994) Estimating discrete-choice models of product differentiation. RAND J Econ 225(2):242-262

Berry S, Levinsohn J, Pakes A (1995) Automobile prices in market equilibrium. Econometrica 63(4):841-890

Bockstael NE, Opaluch JJ (1983) Discrete modeling of supply response under uncertainty-the case of the fishery. J Environ Econ Manage 10(2):125-137

Coleman FC, Koenig CC, Collins LA (1996) Reproductive styles of shallow-water groupers (Pisces: Serranidae) in the eastern Gulf of Mexico and the consequences of fishing spawning aggregations. Environ Biol Fishes 47(2):129-141

Costello C, Polasky S (2008) Optimal harvesting of stochastic spatial resources. J Environ Econ Manage 56(1):1-18

Curtis R, Hicks RL (2000) The cost of sea turtle preservation: the case of Hawaii's pelagic longliners. Am J Agric Econ 82(5):1191-1197

Dillman DA (2000) Mail and internet surveys: the tailored design method. 2nd ed. Wiley, New York

Dupont DP (1993) Price uncertainty, expectations formation and fishers' location choices. Mar Resour Econ 8:219-247

Eales J, Wilen JE (1986) An examination of fishing location choice in the pink shrimp fishery. Mar Resour Econ 2:331-351

Eggert H, Tveteras R (2004) Stochastic production and heterogeneous risk preferences: commercial fishers' gear choices. Am J Agric Econ 86(1):199-212

Hannesson R (1998) Marine reserves: what would they accomplish?. Mar Resour Econ 13(3):159-170

Haynie AC, Layton DF (2010) An expected profit model for monetizing fishing location choices. J Environ Econ Manage 59(2):165-176

Hicks RL, Schnier KE (2006) Dynamic random utility modeling: a Monte Carlo analysis. Am J Agric Econ 88(4):816-835

Holland DS (2004) Spatial fishery rights and marine zoning: a discussion with reference to management of marine resources in New England. Mar Resour Econ 19(1):21-40

Holland DS, Sutinen JG (2000) Location choice in New England trawl fisheries: old habits die hard. Land Econ 76(1):133-150

Kahui V, Alexander WRJ (2008) A bioeconomic analysis of marine reserves for Paua (Abalone) management at Stewart Island, New Zealand. Environ Resour Econ 40(3):339-367

Larson DM, Sutton WR, Terry JM (1999) Toward behavioral modeling of Alaska groundfish fisheries: a discrete choice approach to Bering Sea Aleutian Islands trawl fisheries. Contemp Econ Policy 17(2):267-277

McFadden D, Train K (2000) Mixed MNL models for discrete response. J Appl Econom 15(5):447-470

Mistiaen JA, Strand IE (2000) Location choice of commercial fishermen with heterogeneous risk preferences. Am J Agric Econ 82(5):1184-1190 
Murdock J (2006) Handling unobserved site characteristics in random utility models of recreation demand. J Environ Econ Manage 51(1):1-25

Smith MD (2002) Two econometric approaches for predicting the spatial behavior of renewable resource harvesters. Land Econ 78(4):522-538

Sanchirico JN, Wilen JE (2001) A bioeconomic model of marine reserve creation. J Environ Econ Manage 42(3):257-276

Smith MD (2005) State dependence and heterogeneity in fishing location choice. J Environ Econ Manage 50(2):319-340

Smith MD, Wilen JE (2003) Economic impacts of marine reserves: the importance of spatial behavior. J Environ Econ Manage 46(2):183-206

Smith MD, Wilen JE (2004) Marine reserves with endogenous ports: empirical bioeconomics of the California sea urchin fishery. Mar Resour Econ 19(1):85-112

Smith MD, Wilen JE (2005) Heterogeneous and correlated risk preferences in commercial fishermen: the perfect storm dilemma. J Risk Uncertain 31(1):53-71

Smith MD, Wilen JE, Zhang J, Coleman FC (2006) Effectiveness of marine reserves for large-scale fisheries management. Can J Fish Aquat Sci 63(1):153-164

Smith MD, Wilen JE, Zhang J, Coleman FC (2007) Structural modeling of marine reserves with Bayesian estimation. Mar Resour Econ 22(2):121-136

Strand IE (2004) Spatial variation in risk preferences among Atlantic and Gulf of Mexico longline fishermen. Mar Resour Econ 19:145-160

Timmins C, Murdock J (2007) A revealed preference approach to the measurement of congestion in travel cost models. J Environ Econ Manage 53(2):230-249

Ward JM, Sutinen JG (1994) Vessel entry-exit behavior in the Gulf-of-Mexico Shrimp fishery. Am J Agric Econ 76(4):916-923

Weninger Q, Waters JR (2003) Economic benefits of management reform in the northern Gulf of Mexico reef fish fishery. J Environ Econ Manage 46(2):207-230

Wilen JE, Smith MD, Lockwood D, Botsford L (2002) Avoiding surprises: incorporating fishermen behavior into management models. Bull Mar Sci 70:553-575 